\title{
Fåhraeus medal presentation 2007
}

The European Society for Clinical Hemorheology and Microcirculation has been entrusted with the Fåhraeus Medal Award to be awarded to an outstanding leading scientist in the field of Clinical Hemorheology. All the members of the Council and of the Advisory board of the European Society for Clinical Hemorheology and Microcirculation and the previous recipients of the Award have been entitled to vote. Every one of them has been invited to voter at the procedure, provided by the President of the Society during the first and the second vote.

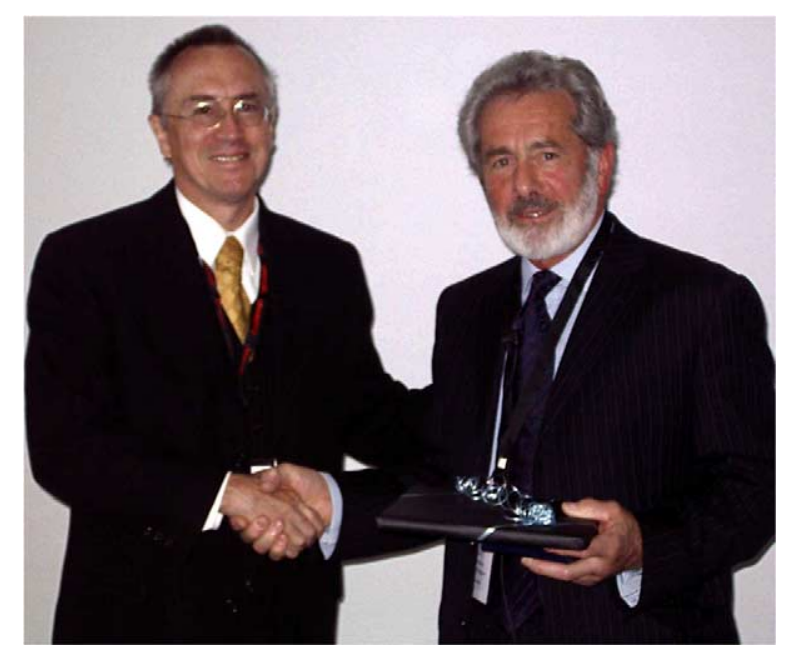

Fig. 1. Friedrich Jung and Mike Rampling.

The nomination of the candidates and the election has resulted from two secret postal ballots. All the collected anonymous closed envelopes have been opened in an official way at the presence of the board of the German Society for Clinical Hemorheology and Microcirculation. The candidates, receiving the greatest number of nominations have been calculated during the first and second ballot. It is my pleasure and a great honour to present you the name of the winner and the 13th Fåhraeus medallist who is Professor Mike Rampling. Saying this I would like to invite Prof. Dirk Seiffge and Prof. Herb Meiselman for the laudation.

Dresden

Friedrich Jung President of the 14th Conference for Clinical Hemorheology and Microcirulation President of the European Society for Clinical Hemorheology and Microcirulation 